\title{
A Queer and Feminist Defense of Being Anonymous Online
}

\author{
Jessa Lingel \\ University of Pennsylvania \\ lingel@upenn.edu
}

\begin{abstract}
From the earliest days of digital communities, online abuse has been connected to anonymity. While concerns around the impact of anonymity, particularly for women, people of color and LGBTQ folks, is legitimate, this paper argues that a flat rejection of digital anonymity is problematic, foreclosing certain forms of queer and feminist praxis. To make this case, I turn to the platform politics of Craigslist. Using Craigslist as a case study, I discuss the persistent stigma attached to online anonymity, before addressing specific tactics of online anonymity associated with queer and feminist values of privacy and mutual aid. Drawing on accounts of Craigslist users who saw anonymity as a protective form of control over their personal information, I outline ways in which anonymity is not solely an enabler for misogyny and homophobia, and can instead (or rather, also) be a subversive tool for self-expression and intimacy.
\end{abstract}

\section{Introduction}

In the context of digital culture, feminism and anonymity are typically seen as fundamentally opposed. While online harassment is neither entirely anonymous nor focused exclusively on women, anonymous trolling practices have persistently been connected to misogynist and anti-feminist behavior [1] [2] [3]. Women are more likely to be harassed online [4], which is even more true for women of color and LGBTQ women [5]. More broadly, feminist politics frequently call for transparency in terms of institutional operations and governance [6]. Decision-making processes that take place behind closed doors are, in this argument, more likely to favor the status quo and protect privilege, as opposed to transparent processes that are more susceptible to pressure for inclusivity. In the context of a tech industry that is dominated by cis white men [7], feminists have multiple reasons to see digital anonymity as a technological and social condition that allows for bias, harassment, stalking and violence.
Anonymity has also been described as a key factor in homophobic and transphobic trolling. Visibility has emerged as a broad strategy for LGBTQ activists, where public recognition of queer and trans people has led to increased rights and freedoms [8]. The trickiness of public visibility is that it can serve as a powerful form of community building or issue amplification, and at the same time turn participants into targets. For example, gay and lesbian bars are powerful symbols of visibility and community that can also draw attention in the form of violence and harassment [9]. Visibility presents similar intensions online. While online communities have been an important part of finding social support and resource sharing for queer and trans people [10] [11], digital technologies have also opened the door to surveillance and harassment of LGBTQ people. With visibility linked to increased freedoms and anonymity linked to trolling, it's unsurprising that many queer and trans people prefer online interactions that push for transparency and verified identities.

Is anonymity inherently anti-feminist and antiqueer? Can anonymity ever be part of queer and feminist ethics of care and solidarity? This paper argues that anonymity is not a monolith behavior while anonymity has inarguable connections to biased and misogynist behavior, it can also be part of a queer and feminist digital toolkit. Particularly for those who occupy multiple vectors of marginality, anonymity can be an important tool for privacy, self-expression and solidarity.

As a way of conceptualizing a queer and feminist politics of anonymity, I focus on the platform politics of Craigslist. A holdout of 1990s internet politics, Craigslist's user policies reflect early web ideas about anonymity. As opposed to the verified IDs and facial recognition of Facebook and Instagram, Craigslist is anonymous by default. When Craigslist launched in 1996, its policies on anonymity were in keeping with norms of the wider web. As Craigslist held on to these early rules of digital culture, new norms around online identity took hold, which supported a persistent label of stigma on platforms that stuck to earlier norms around anonymity. Using Craigslist as a case study, we can see the different risks and affordances offered by anonymity and consider how their user policies play 
out for people on the margins. With a more nuanced understanding of anonymity, we can consider potential modes of resistance, protection and play that can be mobilized by queer and feminist communities.

This paper is part of a larger investigation into Craigslist and its platform politics [12] [13] [14]. Methodologically, I draw on a range of qualitative techniques to develop an analysis of anonymity on Craigslist. Between 2017 and 2019, I conducted 37 interviews with ordinary Craigslist users about their experiences buying, selling and finding work on the platform. I also interviewed a number of Craigslist experts and insiders $(n=8)$, including its founder, Craig Newmark. My discussion draws heavily on textual analysis of a reddit forum dedicated to Craigslist, and on interviews with and editorials by sex workers who used the platform to meet clients. Together these sources provide a multi-faceted account of anonymity and marginalized identities.

I begin with a brief discussion of the sociotechnical politics of online anonymity before turning to the platform policies of Craigslist. After discussing the relationship between Craigslist, anonymity and stigma, I turn to tactics of anonymity that support queer and feminist ethics of self-care, community aid and intimacy.

Before continuing with my arguments, I want to clarify the conceptual links that I bring together in this paper between feminism and queerness. hooks [15] defined feminism as "the movement to end sexism, sexual exploitation and sexual oppression" (p. 33). Ahmed [16] has defined queer ethics as a way of encountering others; rather than thinking of a stranger or outsider as someone unrecognizable, otherness is always rooted in something familiar (See also [17]). For the purposes of this paper, I see feminist and queer ethics as linked in their commitments to solidarity with historically-marginalized communities and identities, where recognition of difference is a beginning, rather than a closure, to support and relationality.

As a set of politics or ethics, queerness and feminism each contain broad and multi-faceted coalitions. While I do not have the space in this paper for an extended discussion of these discourses, it is important to recognize that feminism has been substantively critiqued for prioritizing white, middle and upper class cis and straight women, and failing to recognize or include the queer, trans and BIPOC perspectives [15] [18]. Similarly, queer politics have frequently emphasized the experiences and priorities of cis, white men while ignoring lesbians and trans people, as well as bisexuality and the complexities of intersectional subjectivities [18]. Moreover, feminist and queer politics have often been in opposition, for example in the efforts of so-called trans-exclusionary radical feminists ("so-called" because it is contested that these views are either radical or feminist - See [16]).

By joining feminist and queer ethics as a framework in this paper, I do not mean to suggest either a cohesive set of politics in either camp, or that any alliance between these two coalitions has been consistently stable. Yet amid these complexities and controversies, I contend that there are overarching sympathies and tendencies. For the purposes of the following analysis I see a queer, feminist critique of digital anonymity as an orientation towards critiquing power dynamics that privilege some perspectives over others, with an ethical commitment to inclusion and equity.

\section{Changing Norms of Online Anonymity}

While there was never a time when online anonymity was seen as entirely unproblematic, it didn't always have the overwhelmingly negative reputation it has at present. In part, this is because the sociotechnical politics of anonymity have shifted significantly between the popularization of the internet in the 1990s and the more commercialized, selfpromotional norms of contemporary digital culture. Early internet research often focused on anonymity as a tool for experimenting with identity (e.g. [21] [22]). In the chatrooms (called MUDs or MOOs) of the early internet, users picked pseudonyms and avatars, sometimes opting to reflect their offline bodies and identities, but often not. Importantly, the capacity for playful self-expression could also lead to offensive, superficial and stereotypical portrayals of other genders, races, nationalities and sexualities [23] [24].

Reflecting on pioneering internet studies researcher Sherry Turkle's work on early web culture, Kennedy [25] noted

Turkle argued that in anonymous MOOs and MUDs, people can disguise aspects of identity which might lead to discrimination, such as race or gender, and so can perform a range of identity positions, hiding marginal identities and becoming part of the mainstream. Implicit in Turkle's claim is the assumption that anonymity in cyberspace is potentially empowering: because we cannot see each other, we cannot judge each other; consequently, virtual worlds are equalizing. ( $\mathrm{p}$. 864)

Writing in the early 90s, researchers like Turkle hadn't anticipated a web where online disclosures were tied to offline identity markers. Contemporary practices of doxing and swatting - posting someone's personal information online, sending a SWAT team to 
someone's house - posed extremely difficult technical challenges in the 1990s.

Aside from the technical ability to find and share personal information, anonymity has taken on a set of political implications that overshadow earlier associations with playfulness and experimentation. Kennedy [25] argued that "The problem with the concept of anonymity is that it is too fixed and stable: ... internet identities either are, or are not, anonymous." (p. 871). For Kennedy, the important distinction to be made is between being anonymous and feeling anonymous, where the first is technical and the second is social or cultural. In other words, Kennedy separates (1) having one's identifying information kept private and (2) a social compact that promotes free expression or a set of circumstances where discovery of online content is unlikely. This latter category is sometimes called practical obscurity [26], meaning that information is technically available but finding it is so sufficiently difficult as to be practically hidden. Broadly speaking, early internet conversations were all kept practically obscure because of the small number of people online and a pervasive norm of pseudonyms.

In this paper, I argue for a different distinction between forms of anonymity. Rather than being and feeling anonymity, I'm interested in different political or ethical motivations afforded by or made manifest in anonymity. Elsewhere, I have argued that debates around anonymity have failed to separate anonymity as a harmful way of being from anonymity as a tool of privacy. Here, I argue that the stigma around online anonymity is so entrenched - so fixed and stable, to echo Kennedy - that it forecloses more radical possibilities.

In the specific context of feminist and queer identities online, anonymity has allowed for experimentation [27] and self-expression as well as fetishistic identity tourism [23]. Within the vast landscape of digital culture, women and feminists have carved out online spaces for building community and developing political ideologies [1] [28] [29]. As an example of how anonymity has evolved for feminists involved in digital culture, we can turn to blogging, which has been distinctly (although not solely) popular among women. Novoselova and Jenson [30] observed a transition from pseudonymous to identifiable authorship among feminist bloggers. The authors contend that this shift to disclosing names is in keeping with a neo-liberal push for self-promotion, but comes with the risk of increased vulnerability to harassment.

For feminist activists, anonymity can be both a threat (in terms of harassment) and a goal (in terms of cybersecurity practices - see [31]). In a discussion of digital activism and the lives of ordinary women in
South Africa, Radloff and Gathoni [32] provided a comprehensive account of anonymity's potential for women and feminists. They argued that anonymity is a powerful notion, especially for people who are at risk. It gives us safety in some way. It is also critically important as it allows women in abusive relationships to get help anonymously and to search for information without revealing their identity. In online chatrooms and special focus groups, women can ask a question they would never ordinarily ask. This inserts a sense of power for people who have little power. And as feminists, we know how important this is. We see how power circulates and how anonymity is an important tactic in that regard. (p. 96)

This account is a powerful counter-case to the dismissal of anonymity as solely or predominantly a strategy of abuse, and instead insists on the capacity for anonymity to be radical and feminist.

Many of these affordances identified by Radloff and Gathoni [32] are also powerfully relevant for queer internet users and activists: online anonymity has played an important role in queer dating cultures, such as cruising and cottaging [35] and provided important forms of social support for LGBTQ groups and queer activism [11].

If anonymity allows for radical connectivity and organizing, why has it been dismissed as a tool for trolls? Why has anonymity fallen out of prevalence in mainstream digital cultures? More than any other single intervention, the incredible popularity of Facebook drove a key shift in how anonymity was generally viewed online. Because using Facebook originally required an affiliation with Harvard University, users automatically surrendered their anonymity by joining. Over time, Facebook opened up to other universities and eventually everyone over 13 , but the requirement to use one's "real" name, meaning the name on a state-issued ID, remained. As Facebook became more and more dominant, it helped to normalize a view of anonymity as inherently problematic in its facilitation of scams, crime, harassment and trolling.

Debates over anonymity are not solely a matter of personal preference or interpersonal interactions there are important economic and financial drivers that limit users' options online. As a larger number of platforms have come to rely on targeted advertising for a profitable business model, reliable and granular information about users is crucial. It may in fact be true that Facebook wants users to be identifiable to each other online as a means of limiting harassment, bullying and scams. But it is also true that their business models are predicated on connecting a user to 
her online activity. In this sense, delegitimizing anonymity benefits the profit strategies of Big Tech.

Anonymity has always been a double-edged sword, providing important forms of expression and privacy while also facilitating problematic behavior. Increasingly, a complex and nuanced view of anonymity has been displaced by a one-sided narrative. Queer and feminist ethics and priorities are often positioned as key justifications for rejecting anonymity. But as Radloff and Gathoni [32] have pointed out, "as feminists, we need to acknowledge and also to explore the complexity of the internet in relation to the debates around anonymity" (p. 96). As a way of exploring this complexity in a grounded way, I turn to the different perceptions of anonymity particularly as related to marginalized perspectives tied to Craigslist.

\section{Craigslist's platform politics}

With six hundred billion annual page views, Craigslist is the 18th most visited website in the United States [33]. Originally created as an email list publicizing local events in San Francisco, Craigslist grew into a multi-faceted website with classified advertising sections devoted to job opportunities, rentals and real estate, goods for sale and goods wanted, community events and announcements, personal ads and missed connections, and a variety of discussion boards. Craigslist replicates this same structure for over seven hundred local Craigslist sites in seventy countries, and users post over eighty million classified advertisements on them each month [34].

Functionally, people post classified advertisements in simple bulletin forums, and interested users reply to the poster through a temporary email address autogenerated by Craigslist. Unlike the Craigslist marketplace, they are not locally bounded, and users from all over the world may post on the same board. Craigslist discussion boards are analogous in structure to Usenet or Reddit forums: user reply directly to one another's posts, and their conversations are rendered in extended threads. Discussion board topics range from art and literature to health and spirituality. In terms of its aesthetics, Craigslist's interface is famously unassuming and has remained incredibly stable over its long (for the web) history.

A staff of approximately forty people maintains the Craigslist platform in San Francisco under the leadership of CEO Jim Buckmaster, who took over from founder Craig Newmark in 2000 [34]. Craigslist has been a pioneer in peer-to-peer online transactions and still dominates the field of internet marketplaces, despite increasing competition from sites like
Nextdoor, Internet Yardsale, TaskRabbit and local Facebook groups.

Craigslist's business model, aesthetics and user policies reflect the early web values of the 1990s. Decisions about the platform's policies and appearance are part of Craigslist's emphasis on stability, and its commitment to preserving key tenets of the early web. In contrast to opaque mechanisms of selling user data to advertisers, Craigslist generates revenue solely by charging small fees for certain ads (such as job posts and real estate listings). Newmark and Buckmaster subscribe to a utilitarian, less-is-more vision of technology. Craigslist's stripped-down isomorphic appearance contrasts sharply with tendencies in Big Tech towards continued updates and newer, more complicated features. Without necessarily meaning to, Craigslist's principles have increasingly come to challenge the mainstream web, which has moved towards commercialization and algorithmic predictability, and away from user autonomy and DIY community-building.

While Craigslist's leadership sees value in sticking to the look, feel and user policies of the 1990s, others see a source of suspicion and stigma. Part of the stigma around Craigslist has to do with persistent connections between anonymity and bad behavior. In his analysis of the sharing economy, Sundararajan [35] described Craigslist as fundamentally lacking in security infrastructure that contemporary web users have come to expect:

Craigslist lacks many elements of today's sharing economy marketplaces. One element stands out most saliently - trust. You may be comfortable using Craigslist to hire someone to move a few boxes ... but as new peer-to-peer services appear, finding services on Craigslist seems increasingly perilous. After all, why hire a cleaner or repair person on Craigslist when you can hire one who has been background-screened? ... On Craigslist, there are no checks and balances. You could be letting anyone into your home. If you don't like the job these providers do, you can choose not to hire them again, but there's nowhere to launch a complaint if something is damaged or stolen." (p. 50-51)

Sundararajan's critique ignores some important issues users can report bad actors to Craigslist, as well as the police and the Consumer Affairs Protection Bureau, and when they do, chances are good that Craigslist will cooperate by handing over IP addresses and support legal action [36]. But Sundararajan's view of Craigslist reflects a changing perspective on sociotechnical norms attached to online identity. It's against this view of anonymity that queer and feminist perspectives reveal distinct and even radical possibilities. 


\section{The stigma and solidarity of using Craigslist anonymously}

In interviews with Craigslist users, participants often described Craigslist as stigmatized. People who used Craigslist were, according to these participants, likely to be seen as desperate or deviant, and the platform as a whole was often viewed as backwards and second-tier. Partly this had to do with Craigslist's old school, outdated aesthetics. But the most salient association that participants made between Craigslist and stigma had to do with anonymity. Criticisms of Craigslist's anonymity policy were driven by two key concerns: scams and the personals section. I'll briefly address the issue of anonymity and scams as a way of explaining Craigslist's approach to community moderation. Tools developed by Craigslist as a response to scams have shaped platform policies and justifications of anonymity. From there, I turn to focusing more deeply on Craigslist personals. More politicized and contentious than Craigslist scams, the personals open up a discussion of whether and how queer and feminist ethics manifest in the anonymity of Craigslist exchanges.

\subsection{Craigslist scams and community moderation}

While the vast majority of Craigslist exchanges go as planned, fraud has been a longstanding problem on Craigslist, as on the internet more generally. Craigslist scams are often variations on the so-called Nigerian 419 email scam: an enthusiastic seller with an elaborate backstory requires immediate payment before sending a valuable and underpriced object. (For more on the 419 email scam, see Burrell [37].) These scammers sometimes utilize fake bank websites, fraudulent checks, and even Potemkin offices (building facades with empty interiors) in order to complete their schemes. Additional scams encountered by people I interviewed included check fraud and phishing.

Many of Craigslist's anti-fraud efforts rely on users taking preventative measures, rather than a platformcentric approach. From Craigslist's perspective, it protects users by keeping them anonymous, and users protect themselves by exercising caution in their interactions with other users. This isn't to say that Craigslist is entirely hands off when it comes to fraud and safety. Posters are required to verify their email addresses before posting, but for scammers and bad actors, socket accounts (addresses with no identifying information) can easily be acquired through major email providers. Craigslist also hosts a site manual for user safety, which contains tactics for recognizing deception, law enforcement resources, and examples of fraudulent messages. It's worth nothing that very few of the participants I interviewed were aware of this user guide.

As with many other mainstream platforms, Craigslist uses flagging as a key line of defense against bad behavior. Users are encouraged to flag advertisements that appear suspicious or are simply mis-categorized. Craigslist (again, like most platforms) does not publish information about how many posts are flagged in a given year or even the specific process of what happens to an ad once it's flagged. Craigslist refers to this system as community moderation and relies on it heavily to monitor site content. Flagging is subject to both purposeful and accidental misuse, meaning that innocuous posts can be taken down due to arbitrary user preferences. For instance, male users sometimes flag personal advertisements in the "women seeking men" section, not because of technical issues but because of sexist, heteronormative views on gender identity [38]. While Craigslist's view is that anonymity preserves user privacy, across the web anonymity is increasingly associated with increased risk of scams and harassment. How do these concerns about anonymity and safety play out for queer people and women in Craigslist's most contested section of ads, the personals?

\subsection{Stigma and Craigslist personals}

In April 2018, Craigslist shut down its longstanding personals section. The platform was responding to legislation passed by the U.S. Congress, meant to crack down on sex trafficking of children. The House bill known as Fight Online Sex Trafficking Act (FOSTA), and the Senate bill, the Stop Enabling Sex Traffickers Act (SESTA), were meant to give victims of human trafficking the tools to investigate and prosecute human traffickers. Under the Communications Decency Act, platforms cannot be held responsible for the bad acts of individual users; FOSTA/SESTA challenged this law, and held that platforms can be held responsible for the activity of users, when attached to human trafficking [25]. Because it is very difficult for Craigslist to ensure that any given personal ad is 100 percent legitimate, the platform opted to shut down the personals section altogether. (Craigslist wasn't alone in making sweeping policy changes - so did Reddit and many online dating sites, like OkCupid and Grindr.)

FOSTA/SESTA was the latest and most drastic response to public outcry over online platforms that can facilitate human trafficking Along with platforms like Backpages, Craigslist has repeatedly been called out for facilitating sex work. Until 2009, Craigslist's 
personals included a subsection called "erotic services," where people openly advertised sex. That year, it changed the name to "adult services" and instituted stricter screening after a medical student in Boston was accused of attacking (and in one case, murdering) several women he met through the site [39]. In many ways, Craigslist's reputation never fully recovered from the controversy over the "Craigslist Killer," and the high-profile case helped cement perceptions that anonymity facilitates violence, particularly against women.

I interviewed over 30 Craigslist users about finding work and buying used goods on Craigslist, but recruiting people who had used the personals section was more difficult. Partly this was because the personals section shut down in April 2018, just as I was conducting interviews. Additionally, and as will become clear in this analysis, Craigslist personals are frequently characterized as seedy, kinky and unreliable. As such, the difficulties of recruiting interviews reflect the stigma surrounding Craigslist in general and the personals in particular. Although I conducted seven interviews conducted with people who had users Craigslist personals, I draw primarily on the reddit forum dedicated to Craigslist. In the immediate aftermath of FOSTA, the Craigslist reddit thread hosted an extended discussion on the end of Craigslist personals. I also use as primary sources interviews with and editorials written by sex workers who used Craigslist.

In the context of Craigslist personals, stigma can apply to queer relationships, extramarital affairs and interests in fetish or kink. As Reynolds [40] has argued in her research on media coverage of Craigslist, "Stigma against online sexuality has been especially pervasive during an era when new technologies and alternative sexualities represent compounded moral threats" (p. 8). Stigmatizing Craigslist personal ads stems from a combination of lingering doubts about online dating, the visibility of non-mainstream relationships and rare but scary instances of violence tied to the platform. Across the different primary sources I've gathered - interviews, the reddit comments and editorials - we see a grappling with Craigslist's role in digital culture, its platform politics and its stigmatized reputation.

The two most common themes on the reddit thread involved discussing alternatives to Craigslist personals and debating the merits of FOSTA. Reddit has frequently been characterized as unruly and rowdy, and a haven for anything-goes discourse [41]. As such, it's perhaps unsurprising that on the whole, opinions about FOSTA were highly critical. A representative post insists that the bill will have negative consequences for online freedom:
[People] hear shit like human trafficking, terrorist, pedophile, yadda yadda and automatically assume 'well this bill must be good, it stops the bad guys.' When in reality it's a legislation of morality ... I've hooked up online with success the only thing this law is going to hinder is civil liberties.

For this commenter, FOSTA/SESTA uses legitimate concerns around sex work and human trafficking in order to conceal a crackdown on internet freedom. Drawing on the stigma around anonymous sex and the internet is central to this dynamic.

The reddit thread on Craigslist and FOSTA includes a number of references to anonymity. Some users were happy to see Craigslist personals go, arguing that ads had gotten too scammy and unreliable. Others saw advantages to anonymity. One poster noted, "i met my husband on $\mathrm{Cl}$ personals! some of us weirdos like the anonymity damnit!" Echoing other commenters who wondered about online platforms that would replace Craigslist personals, one user highlighted the need for anonymity in any competing platform: "Staying tuned for whatever the alternative is going to be. I need a place to read/share kinky shit that allows for true anonymity." Another user defended Craigslist's use of anonymity in the personals section, writing "Getting married next year to my CL personals hook up! Anonymous and not nearly as much fuss and bother as online dating apps like OkCupid." While it's unclear what precisely the third commenter means by the "fuss and bother" of OkCupid, Craigslist is positioned as preferable because it is simpler and less complicated. All of these comments categorize anonymity as a positive feature, allowing for experimentation and privacy.

Multiple comments on the reddit thread saw particular value in anonymity for LGBTQ users. Queer and trans people use online dating almost twice as often as their straight and cis peers [42]. Within the landscape of online dating, Craigslist occupied a particular role, allowing for experimentation and selfexpression. Two themes surfaced in these comments, the first around experimentation and the second around privacy. Regarding the first, one user wrote, "I can only imagine how hard it [will] be for people struggling with their sexuality. Craigslist was an outlet for them ... It's a unique type of outlet, where people could express them self freely and anonymously." For people whose sexualities and preferences were marginalized, Craigslist was a space of freedom and non-judgement. As one user explained, "The freaks were the best thing about Craigslist. At least in the gay section. You could post something as ridiculous as you want someone to come over and do jumping jacks in the nude and by god someone would be there within the hour. It was a crazy place." 
A second theme around the value of anonymous personals for LGBTQ folks emphasized privacy. As one redditor stated, "This is a HUGE blow to the LGBT community, especially us that aren't out." In this view, anonymity matters deeply as a form of protection for people who had grown up in a time or place where queer sexualities were viewed as offensive or immoral. As another poster explained, "btw married men on there looking for sex with other men are gay or at least bi. They grew up in a society where they couldn't be who they truly were." One user described Craigslist personals as more or less useful based on where someone lives:

The funny thing is I found the nyc M4m [men seeking men section in New York City] one of the worst. It was so hard to find guys in there ... they have so many outlets [in New York City] I guess. Whereas take a place like Ames, Iowa [is] just crawling with guys needing everything from hand jobs to anon light low BJ to glory holes that they build in their garage. American ingenuity at its finest!

In this account, Craigslist fills a niche roll not just for men who have sex with men, but for men who have sex with men in cities or towns without a visible or sizeable LGBTQ population. Anonymity is a crucial advantage in precisely these circumstances - being exposed as a man who has sex with men in a city like New York City comes with much fewer risks than being exposed in a place where queer identities are heavily stigmatized.

For young LGBTQ internet users, who have grown up with more tolerance for queer and trans people, platforms that reveal a great deal of personal information about users may not seem risky, while platforms that hide someone's identity might seem problematic. But for people who grew up in a moment when homosexuality and queerness were seen as transgressive, or for people located in places that are still largely intolerant of LGBTQ identities, the anonymity of Craigslist was an important feature.

Another component of Craigslist's value to people on the margins has to do with the platform's emphasis on texts over images. Following trends in social media more broadly, online dating platforms have transitioned towards algorithmic prediction and verified identities. While early online dating platforms were (by necessity) text-based, images have become central to online dating. For many platforms, identifying images are not just encouraged but required. Although users often value images in seeking partners, the emphasis on visual information can lead to racism, classism, femme and fat phobia, as well as other forms of discrimination [43]. Even after
Craigslist added the ability to include images on ads, the personals continued to rely heavily on text.

By privileging text over images, Craigslist offers more privacy to its users, which is important for LGBTQ people, as well as others whose interests or bodies don't conform to stereotypical or mainstream preferences. As one reddit commenter noted:

While I did have some super weird experiences and emails through CL's personals, I was able to pretty much find [hookups] who were fine with my being obese. They were chill and didn't judge me for it. Hell, sometimes we had decent convos too. Guess

I'm screwed until an alternative comes around.

Other users agreed that anonymity and text-based rather than imaged-based communication allowed users to connect in terms of personality and shared interests rather than how people looked.

The queer ethics of anonymity that emerge in Craigslist's personals section emphasize user - versus platform - autonomy. Anonymity gives users increased privacy, supporting the need for self-expression. It also allows queer users to control the process of disclosing personal information. Rather than a platform dictating required information, users can determine what information to share and with whom.

Fears of anonymity on Craigslist are often deeply gendered. In the U.S., and Western societies more broadly it's women's bodies (and in particular, white women's bodies) that are generally positioned as needing protection in public [44]. Although women are much more likely to be attacked by people they know (for example, intimate partner violence is much, much more common than sexual assault by strangers), violence in public is undoubtedly a concern for sex workers, whose profession is exceptionally dangerous. If we want to take seriously the feminist potential of anonymity, we should commit to understanding how people who stand to lose the most from anonymous online encounters view this feature.

In the context of feminist ethics, sex work can provoke complicated responses. Citing the capacity for violence and exploitation, some feminists argue that sex work is inherently in service of patriarchal and misogynist narratives around sex. For others, sex work allows women to take advantage of a niche in the marketplace, and represents a self-determined form of making money, as well as a potentially meaningful form of sexual self-expression. The messy reality is that some forms of sex work are deeply exploitative while others can be liberatory and empowering. Reasonable feminists can disagree on the radical capacity of sex work, and to be clear, it shouldn't be assumed that sex workers generally identify as feminists. But whatever one's view on the ethics of sex work, the question of whether a given technology can 
make the lives of sex workers better should at the very least consider their views and experiences. Moreover, the language that sex workers use to describe what they do and don't want in terms of regulation often contain overtly feminist language and values.

When Craigslist was negotiating its adult services policies in 2009, journalist and former sex worker Melissa Gira Grant defended the platform as a better alternative than its less responsible peers. Grant [45] argued that

Far from unregulated public sex, each [Craigslist] interaction had to begin with a few emails and, often, a light background check. These transactions might not always have gone as advertised, but they were rarely harmful or resulted in headlines.

Rather than a dangerous free-for-all, Grant described Craigslist as a point of mediation that allowed sex workers to screen potential clients. In a separate post, Gira Grant argued that Craigslist was an invaluable service because, "a service that allows a sex trade worker to take control of his or her own business by deciding when to work, who to accept as a client, and how much to charge for that labor is a valuable tool in giving people power over the conditions of their labor" [45]. Anonymity here is a key factor that allows for more control over one's clientele, and by extension, his or her labor.

According to a 2010 blog post by Trixie the Anonymous Domme, craigslist was deeply valued by sex workers, particularly by newcomers. Anonymity played a key role in ensuring that sex workers had more agency and privacy about their clients and identities:

The greatest threat to sex workers is when they don't have the ability to screen or have a say in the clients they see ... The beauty of Adult Services, compared to other listing sites such as Backpage or CityVibe, was that a provider was in total control over how much information she wanted to share. The anonymous email feature and automatic expiration specific to $\mathrm{CL}$ ads meant that posters could communicate with prospective clients without giving away information that would make them vulnerable to stalking — or allow their temporary choice to haunt them on the Internet for eternity. [46]

For sex workers, anonymity offers many forms of protection. In the short term, anonymous email exchanges allow sex workers to determine whether a prospective client seems trustworthy, while keeping personal information private. In the long term, defaulting to anonymity means that there's no online profile to document one's history as a sex worker.
Reacting to the 2018 decision to close Craigslist personals, one sex worker insisted that online platforms played a crucial role in allowing sex workers to look out for one another: "These sites (are) the way that we connect. We can mentor each other. We can support each other" (cited in [47]). Another sex worker contrasted the ability to screen clients through Craigslist communications with the limited ability to gather information from first impressions of physical encounters: "most often, physical appearance and demeanor really don't tell you a whole lot. The internet completely changed that" (cited in [47]).

In support of these claims from women who work in the sex industry, sociologists and economists have analyzed the consequences for sex workers when an online platform like Craigslist closes. Cunningham and Kendall [48] found that violence against sex workers actually increases as a result of platform shutdowns because sex workers have fewer tools for screening potential clients and are forced to rely on pimps.

Feminist ethics of anonymity, as expressed in the context of Craigslist personals, share key priorities with the queer ethics outlined earlier. Anonymity allows for more control over sensitive information and the ability to screen potential clients without revealing private data. An additional affordance that sex workers valued was that anonymity allowed ads to be public and thus could support community input. This argument meant that flagging could be a tool for community aid, and not just a form of discriminatory censorship.

\section{Conclusions}

The central goal of this paper has been to contest a one-dimensional and unilateral perspective on anonymity. Beyond simply insisting that anonymity is more complicated than the reductive moral accounting that's become dominant in the mainstream web, I have sought to lay out its potential for distinctly feminist and queer politics. Key to feminist ethics are practices of supporting and amplifying the voices of historicallymarginalized groups [49]. Focusing on digital technologies, feminist ethics have emphasized equitable, inclusive design [50]. Turning to queer politics, in the context of universities and diversity work, Ahmed [51] has introduced the concept of queer use. As a concept, queer use involves reanimating calls for diversity as the everyday but painstaking labor of reorienting institutions towards those who have been systematically excluded. In this article, I argue that there are queer and feminist uses for anonymity online.

When we amplify the voices of LGBTQ folks and sex workers as part of a push for more inclusive tech, we gain a robust defense of anonymity online. And at 
the same time, we see how a one-dimensional view of anonymity forecloses the more radical tactics that it enables. For platforms that insist on their commitments to marginalized communities, anonymity presents a challenge - it has clear value to users on the margins but challenges the most fundamental logics of Big Tech. An explicitly queer and feminist defense of anonymity is an excellent vantage point for diagnosing socio-technical power dynamics. We can identify the intended users of a platform, and those who are left out of the design plans [50]. More than just identifying stakeholders, we can see how the differences in their relative power shapes not only their relationships to the platform, but the ways that different practices and policies become normalized. What's at stake in rules around anonymity is nothing short of whose uses of the web are held up as legitimate, and whose uses of the web are dismissed as backwards, problematic or even criminal.

While craigslist's general reputation for scams and fraud plays into a view of anonymity as problematic, a more nuanced view surfaces from a discussion of anonymity on craigslist personals. Without denying that the personals section can be seedy and unreliable, analysis of how marginalized users think of Craigslist's policies reveals how anonymity can be a form of privacy and a source of autonomy. What's politically salient in these discourses are the beneficiaries of anonymity: LGBTQ people and sex workers. If groups that have been consistently targeted by anonymous attackers nevertheless see a powerful value in this same affordance, perhaps more platforms should create more spaces for anonymity online.

\section{References}

[1] R. Clark-Parsons, "Building a Digital Girl Army: The Cultivation of Feminist Safe Spaces Online", New Media \& Society, 2018, 20(6), pp. 2125-2144.

[2] A. Marwick, "None of This is New (Media): Feminisms in the Social Media Age", In A. \& T. Oren. (eds), The Handbook of Contemporary Feminism, Routledge, New York, NY. In Press.

[3] W. Phillips, This is Why We Can't Have Nice Things: Mapping the Relationship Between Online Trolling and Mainstream Culture, Cambridge, MA: MIT Press, 2015.

[4] D. Antunovic, “'We Wouldn't Say it to Their Faces': Online Harassment, Women Sports Journalists, and Feminism”, Feminist Media Studies, 2019, 19(3), pp. 428-442.

[5] S. Madden, M. Janoske, R. B. Winkler, \& A. N. Edgar, "Mediated Misogynoir: Intersecting Race and Gender in Online Harassment", In Mediating Misogyny (pp. 7190), Palgrave Macmillan, Cham, 2018.

[6] J. Halley, P. Kotiswaran, R. Rebouché, \& H. Shamir, Governance Feminism: An Introduction, University of Minnesota Press, Minneapolis, MN, 2018.
[7] E. Chang, Brotopia: Breaking Up the Boys' Club of Silicon Valley, Portfolio, New York, NY, 2019.

[8] A. Lind, "'Out' in International Relations: Why Queer Visibility Matters", International Studies Review, 2014, 16(4), pp. 601-604.

[9] J. J. Gieseking, "Crossing Over Into Neighbourhoods of the Body: Urban Territories, Borders and Lesbian-Queer Bodies in New York City", Area, 2016, 48(3), pp. 262270.

[10] M. L. Gray, Out in the Country: Youth, Media, and Queer Visibility in Rural America. NYU Press, New York, NY. 2009.

[11] V. Kitzie, "'I Pretended to be a Boy on the Internet': Navigating Affordances and Constraints of Social Networking Sites and Search Engines for LGBTQ+ Identity Work", First Monday. 2018.

[12] J. Lingel, "Notes from the Web that Was: The Platform Politics of Craigslist", Surveillance \& Society, 2019, 17(1/2), pp. 21-26.

[13] J. Lingel, An Internet for the People: The Politics and Promise of Craigslist, Princeton University Press: Princeton, 2020.

[14] J. Lingel, "Socio-technical Transformations in Secondary Markets: A Comparison of Craigslist and VarageSale", Internet Histories, 2019, 3(2), pp. 162 179.

[15] b. hooks, Feminism is for Everybody: Passionate Politics, Pluto Press, New York, NY, 2000.

[16] S. Ahmed, Strange Encounters: Embodied Others in Post-coloniality, Psychology Press, London, 2000.

[17] P. MacCormack, "The Queer Ethics of Monstrosity," In Speaking of Monsters", (pp. 255-265), Palgrave Macmillan, New York, NY, 2012.

[18] T. N. Young, Black Queer Ethics, Family and Philosophical Imagination, Springer, New York, NY, 2016.

[19] K. W. Crenshaw, On Intersectionality: Essential Writings, The New Press, New York, NY. 2017.

[20] I. Murti, "Feminism that Excludes Trans Women is Bigoted, Not Radical", The Swaddle, 2019. Retrieved from https://theswaddle.com/feminism-that-excludestrans-women-is-bigoted-not-radical/

[21] L. Kendall, 'Meaning and Identity in 'Cyberspace': The Performance of Gender, Class, and Race Online", Symbolic Interaction, 1998, 21(2), pp. 129-153.

[22] S. Turkle, Alone Together: Why We Expect More From Technology and Less From Each Other, Hachette UK, London, 2017.

[23] L. Nakamura, "Race in/for cyberspace: Identity Tourism and Racial Passing on the Internet", Works and Days, 1995, 13(1-2), pp. 181-193.

[24] L. Nakamura, Cybertypes: Race, Ethnicity, and Identity on the Internet. Routledge, New York, NY, 2013.

[25] H. Kennedy, Beyond Anonymity, or Future Directions for Internet Identity Research, New Media \& Society, 2006, 8(6), pp. 859-876.

[26] N. S. Marder, "From Practical Obscurity to Web Disclosure: A New Understanding of Public Information”, Syracuse L. Rev., 2008, 59, pp. 441. 
[27] J. Berman, \& A. S. Bruckman. "The Turing Game: Exploring identity in an online environment", Convergence, 2001, 7(3), pp. 83-102.

[28] A. Marwick, \& R. Lewis, "Media manipulation and disinformation online", Data \& Society Research Institute: New York, 2017.

[29] S. E. Matrix, "Cyberfeminism and Technoculture Studies: An Annotated Bibliography", Women's Studies Quarterly, 2001, 29(3/4), pp. 231-249.

[30] V. Novoselova, \& J. Jenson, "Authorship and Professional Digital Presence in Feminist Blogs", Feminist Media Studies, 2019, 19(2), pp. 257-272.

[31] J. Radloff, "Feminist Engagements with 21st-Century Communications Technology", Feminist Africa, 2013, 18, pp. 1-11.

[32] J. Radloff, \& B. Gathoni, "In conversation", Feminist Africa, 2013, 18, pp. 100-104.

[33] Alexa, "Craigslist", 2019, Retrieved from https://www.alexa.com/siteinfo/Craigslist.org

[34] Craigslist, "About Craigslist", n.d., Retrieved from https://www.Craigslist.org/about/

[35] A. Sundararajan, The Sharing Economy: The End of Employment and the Rise of Crowd-based Capitalism, MIT Press, Cambridge, MA, 2016.

[36] A. Bereznak, "Craig from Craigslist's second act", The Ringer, 2017, Retrieved from https://www.theringer.com/2017/6/1/16042734/craignewmark-interview-Craigslist-journalism421c50020179

[37] J. Burrell, Invisible users: Youth in the Internet Cafés of Urban Ghana, MIT Press, Cambridge, MA, 2012.

[38] M. White, Buy it now: Lessons from eBay, Duke University Press, Durham, NC, 2012.

[39] M. Cramer, \& S. Murphy, "Files tell more about Craigslist Killer", Boston, 2011, Retrieved from http://archive.boston.com/news/local/massachusetts/arti cles/2011/04/01/files tell more about Craigslist killer/

[40] C. Reynolds, "“I am Super Straight and I Prefer You be Too': Constructions of Heterosexual Masculinity in Online Personal Ads for "Straight" Men Seeking Sex with Men", Journal of Communication Inquiry, 2015, 39(3), pp. 213-231.

[41] M. Shelton, K. Lo, \& B. Nardi, "Online Media Forums as Separate Social Lives: A Qualitative Study of
Disclosure Within and Beyond Reddit, iConference 2015 Proceedings, 2015.

[42] P. Leskin, "LGBTQ Adults are Using Dating Apps Nearly Twice as Much as Straight Adults, Pew Study Finds", Business Insider, 2020, Retrieved from https://www.businessinsider.com/dating-apps-useLGBTQ-community-twice-as-much-straight-adults2020-2

[43] S. McGlotten, Virtual Intimacies: Media, Affect, and Queer Sociality, Suny Press, Albany, NY, 2013.

[44] E. Osucha, The Whiteness of Privacy: Race, Media, Law, Camera Obscura: Feminism, Culture, and Media Studies, 2009, 24(1(70)), pp. 67-107.

[45] M. Gira Grant, "How Shutting Down Craigslist's Erotic Services Section Hurts Prostitutes and Cops", Slate, 2009, Retrieved from https://slate.com/technology/2009/05/how-shuttingdown-Craigslist-s-erotic-services-section-hurtsprostitutes-and-cops.html

[46] Trixie the Anonymous Domme, "A Sex Worker on Life After Craigslist", Jezebel, 2010, Retrieved from https://jezebel.com/a-sex-worker-on-life-after-craigslist5644988

[47] M. Nedelman, “After Craigslist Personals Go Dark, Sex Workers Fear What Comes Next," CNN, 2018. Retrieved from https://www.cnn.com/2018/04/10/health/sex-workersCraigslist-personals-trafficking-bill/index.html

[48] S. Cunningham, \& T. D. Kendall, "Risk Behaviours Among Internet-facilitated Sex workers: Evidence from Two New Datasets", Sexually Transmitted Infections, 2010, 86(Suppl 3), pp. iii100-iii105.

[49] S. Ahmed, "Living a Lesbian Life," Feminist Kill Joys, 2015, Retrieved from https://feministkilljoys.com/2015/02/26/living-alesbian-life/

[50] C. D'Ignazio, \& L. F. Klein, Data Feminism. MIT Press, Cambridge, MA, 2020.

[51] S. Ahmed, What's the Use? On the Uses of Use, Duke University Press, Durhamn, NC, 2019. 